\title{
Safety, pharmacokinetics and pharmacodynamics of the selective glucocorticoid receptor modulator AZD7594, following inhalation in healthy Japanese
} volunteers

This article was published in the following Dove Press journal:

Drug Design, Development and Therapy

\author{
Susanne Prothon (D) \\ Ulrika Wählby Hamrén' \\ Ulrika Tehler ${ }^{2}$ \\ Esther Yoon ${ }^{3}$ \\ Henrik Forsman (iD) ${ }^{4}$ \\ Cecilia Arfvidsson (1D $)^{5}$ \\ Ajay Aggarwal ${ }^{6}$ \\ Yingxue $\mathrm{Chen}^{7}$
}

'Clinical Pharmacology, ADME, and Al, Clinical Pharmacology \& Safety Sciences, R\&D, AstraZeneca, Gothenburg, Sweden;

${ }^{2}$ Early Product Development,

Pharmaceutical Sciences, R\&D,

AstraZeneca, Gothenburg, Sweden;

${ }^{3}$ Early Phase Clinical Unit, PAREXEL,

Glendale, CA, USA; ${ }^{4}$ Research and Early

Development, Respiratory, Inflammation and Autoimmune (RIA),

BioPharmaceuticals R\&D, AstraZeneca, Gothenburg, Sweden; ${ }^{5}$ Clinical Sample and Bioanalytical Science, Clinical Pharmacology \& Safety Sciences, R\&D, AstraZeneca, Gothenburg, Sweden; ${ }^{6}$ Research and Early Development, Respiratory, Inflammation and Autoimmune (RIA), BioPharmaceuticals R\&D, AstraZeneca, Boston, MA, USA; ${ }^{7}$ Clinical Pharmacology, ADME, and AI, Clinical Pharmacology \& Safety Sciences, R\&D, AstraZeneca, Boston, MA, USA

Correspondence: Susanne Prothon Clinical Pharmacology, ADME, and Al, Clinical Pharmacology \& Safety Sciences, R\&D, AstraZeneca, Pepparedsleden I, Mölndal 43I 83, Sweden

Email susanne.prothon@astrazeneca.com
Introduction: AZD7594 is a non-steroidal, selective, glucocorticoid receptor modulator (SGRM), currently in development for the treatment of asthma and chronic obstructive pulmonary disease. This paper reports a randomized placebo-controlled dose escalation study in healthy Japanese male subjects.

Methods: Inhaled AZD7594 was administered as one single dose at day 1 (day 1-4), with subsequent multiple daily doses (day 5-16) via a multiple-dose dry powder inhaler for 12 days of once-daily treatment. At each dose level, subjects were randomized to AZD7594 $(n=7)$ or placebo $(n=2)$. The safety, pharmacokinetics $(P K)$ and pharmacodynamics (PD) of AZD7594 were evaluated.

Results: Inhaled AZD7594 was safe and well tolerated up to and including the highest dose $1600 \mu \mathrm{g}$ tested. Plasma exposure suggested dose-proportional PK. The urinary excretion of AZD7594 was negligible $(<0.02 \%)$. Dose-related effects were observed for $24 \mathrm{hrs}$ plasma cortisol; however, significant cortisol suppression $(25 \%)$ was only seen at the highest dose level following multiple doses. There were no or only marginal effects on other biomarkers tested (dehydroepiandrosterone sulfate [DHEA-S] and osteocalcin).

Conclusion: In conclusion, the early clinical evaluation of inhaled AZD7594 suggests that this novel SGRM is well tolerated in the dose range investigated and also in a Japanese population. It shows dose-proportional plasma exposure, moderate accumulation and has limited impact on systemic markers of glucocorticoid activity.

Keywords: systemic activity, AZD7594, SGRM, Japanese, healthy subjects, pharmacokinetics, pharmacodynamics, glucocorticoid receptor modulator

\section{Introduction}

AZD7594 is a novel inhaled non-steroidal, potent and selective glucocorticoid receptor modulator (SGRM) currently in clinical development for the treatment of asthma and chronic obstructive pulmonary disease.

The low solubility and slow dissolution rate of AZD7594 enable prolonged lung retention consistent with once-daily administration. ${ }^{1}$ Lung retention, coupled with low oral bioavailability and a rapid clearance from the systemic circulation, creates a favorable concentration gradient between the lung and the systemic circulation and an opportunity for separation of local and systemic effects. ${ }^{2}$ 
AZD7594 has demonstrated anti-inflammatory effects in preclinical models of inflammation, with a potential for improved therapeutic ratio compared to inhaled corticosteroids (ICS). ${ }^{2}$ AZD7594 has shown favorable safety and tolerability profiles in a first in human study in healthy subjects, ${ }^{3}$ with little evidence of effects of clinical concern that have previously been reported for ICS, such as decreased plasma cortisol. In addition, once-daily administration of AZD7594 was effective at reducing inflammation and improved lung function and asthma-related symptoms in mild-to-moderate asthmatics. ${ }^{4,5}$

This study was conducted to evaluate single- and multiple-ascending dosing (SAD/MAD) in healthy male Japanese subjects, to support inclusion of patients of Japanese origin in the future clinical development program for AZD7594. The primary objective of the study was to investigate the safety and tolerability of inhaled AZD7594. Secondary objectives included a characterization of the pharmacokinetics (PK) of AZD7594 and provisionally assess dose proportionality of the PK, the time required to reach steady state and the degree of accumulation and to investigate the pharmacodynamics (PD) of AZD7594 by assessing effects on the HPA axis and other relevant biomarkers of undesired systemic activity.

\section{Methods}

\section{Study design and subjects}

The trial was conducted in compliance with Good Clinical Practice and the Declaration of Helsinki. The investigators obtained institutional review board approvals (Aspire IRB, Santee, California, USA) for the study protocol (NCT02645253), and the study was conducted at PAREXEL Early Phase Clinical Unit, Glendale, CA, USA, over a period of three months between $12^{\text {th }}$ January 2016 and $17^{\text {th }}$ April 2016. All subjects gave their written informed consent before participating in the trial. This was an openlabel, randomized, Phase I, single-center, single-blind, placebo-controlled, sequential-groups study of single and multiple inhaled ascending AZD7594 doses in 27 healthy male Japanese subjects aged 26-46 years (Figure 1). Subjects were included that met the following criteria: aged between 20 and 45 years with suitable veins for cannulation or repeated venipuncture; born in Japan with Japanese parents and four Japanese grandparents; a body mass index between 18 and $30 \mathrm{~kg} / \mathrm{m}^{2}$ weighing at least $25 \mathrm{~kg}$ and no more than $100 \mathrm{~kg}$. Subjects were excluded if they had a history of any clinically significant disease or disorder, had used systemic glucocorticosteroids within 6 weeks of enrolment or had previously received AZD7594. Three cohorts were dosed (AZD7594 $\mathrm{n}=7$; placebo $\mathrm{n}=2$ ) at the AZD7594 dose level of 200, 400 and $1600 \mu \mathrm{g}$ (delivered dose). Doses were selected based on results from the first in human study. ${ }^{3}$ The randomization scheme was generated using validated internal software, allocating the subjects to AZD7594 or placebo. A single inhaled dose of AZD7594 or placebo was administered on Day 1, followed by once-daily dosing on Days 5-16 (for 12 days). The three dose levels selected were based on a recent dose escalation study in healthy, predominantly Caucasian volunteers. ${ }^{3}$ Safety and tolerability measurements, plasma cortisol, plasma dehydroepiandrosterone sulfate (DHEA-S) and plasma osteocalcin concentrations were reviewed in conjunction with all available safety data by a Safety Review Committee prior to deciding on the next dose.

Safety and tolerability was assessed during the study as adverse events, vital signs, ECG, physical examination, laboratory assessments and lung function test (spirometry). Venous blood samples for analysis of plasma AZD7594 concentrations were taken on Day 1 and Day 16 pre-dose, $0.25,0.5,1,1.5,2,3,4,6,8,12,16,24,36,48,72$ and 96 hrs (h) post-dose; on Days 5-15 at pre-dose; on Days 5, 8 and 12 at $1 \mathrm{hr}$ post-dose. Urine for analysis of AZD7594 concentration was collected on Day 1: pre-dose spot

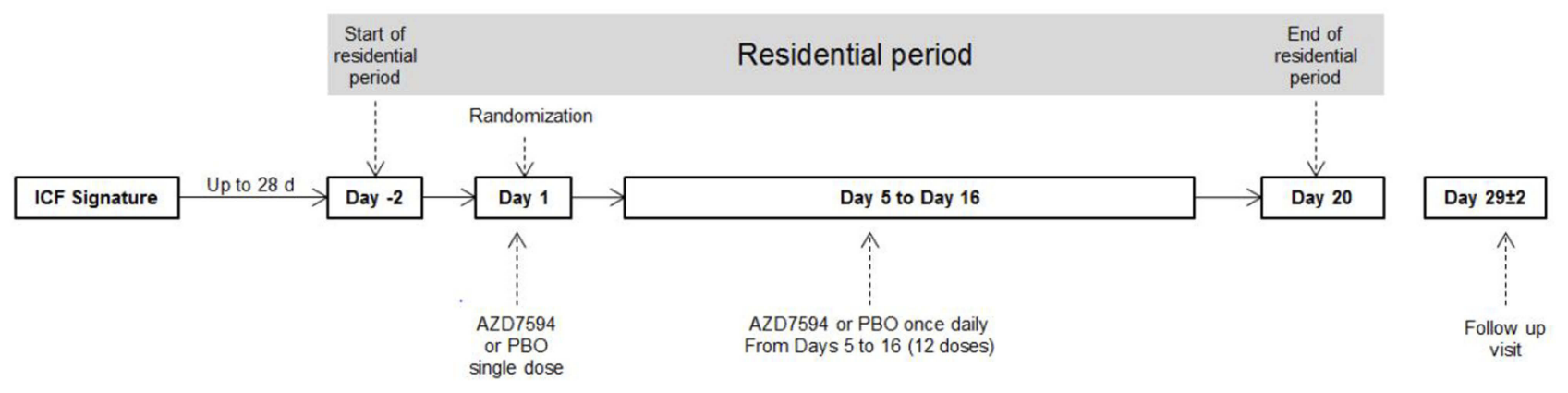

Figure I Study flow diagram. 
collection; and in intervals: $0-6,6-12,12-24,24-48,48$ 72; 72-96 hrs post dose.

To assess the effects of AZD7594 on the HPA axis, venous blood samples for analysis of plasma cortisol concentrations were collected on Day -1 , Day 1 and Day 16 at pre-dose (0), 2, 4, 6, 8, 10,12, 16, 20, 22 and 24 hrs post dose. Venous blood samples for analysis of plasma DHEA-S and osteocalcin were taken on Day 1 at predose and Day 16 at 24 hrs after dose.

The study consisted of three visits: screening (within 28 days of dosing), a residential study period starting two days before the first dose on Day 1 with discharge from the unit on Day 20 and a follow-up visit 27-31 days postdose.

\section{Investigational products and administration}

The investigational compound was formulated as an ordered mixture in a dry powder inhaler (DPI). The inhaled doses of AZD7594 or placebo were administered in the morning via the metered dose SD2FL DPI, containing micronized AZD7594 and lactose carrier, delivered at a dose of $200 \mu \mathrm{g}$ or $400 \mu \mathrm{g}$ AZD7594 per actuation. Thus, the $1600 \mu \mathrm{g}$ dose was given with four actuations. The test subjects were instructed to inhale strongly and deeply through the device.

A planned cohort with the doses administered via a pressurized metered dose inhaler (pMDI) using micronized AZD7594 co-suspended with porous particles in a hydrofluoroalkane propellant was canceled. Emerging data from a device bridging study (NCT02648438) showed unexpectedly low systemic exposure following use of the pMDI inhaler.

\section{Bioanalytical methods}

AZD7594 was quantitated in human plasma and urine samples using validated bio-analytical methods in the laboratories of Covance Laboratories, Harrogate, UK. The plasma method employs protein precipitation followed by liquid chromatography with tandem mass spectrometric (LC-MS/MS) detection in the negative ion mode. The method for urine built on the plasma methodology included an additional sample dilution step, adding Bovine Serum Albumin (BSA) as a stabilizing agent to prevent adsorption. Both methods were validated in the range 10.0 to $10,000 \mathrm{pmol} / \mathrm{L}$ and the lower limit of quantification
(LLOQ) set at $10.0 \mathrm{pmol} / \mathrm{L}$ using $200 \mu \mathrm{L}$ plasma and urine, respectively.

The intra-batch and inter-batch precision for both the plasma and urine quantifications, reported as coefficient of variation $(\mathrm{CV})$, were well below the accepted $\leq 15 \%$ ( $\leq 20 \%$ at LLOQ) at all levels. Intra-batch and inter-batch bias were well within the accepted $15 \%( \pm 20 \%$ at LLOQ) of the nominal concentration at all levels. To verify the reliability of the reported sample analyte concentrations in plasma, and to support the accuracy and precision of measurements established with spiked control samples, incurred sample reanalysis was also performed. It was observed that $90 \%$ of the repeat results and original results were within $20 \%$ of the mean of the two values, which is well within the acceptance criteria in the current regulatory guidance.

For the PD endpoint of assessing effects on the HPA axis plasma cortisol concentrations were determined using Beckman Cortisol assay, a competitive binding immunoenzymatic assay, validated at GenX Laboratories Inc., Los Angeles, CA, USA. The Cortisol Calibration material provided for the instrumentation had the approximate values of: $0,2,5,10,25$ and $60 \mu \mathrm{g} / \mathrm{dL}$. The intra-batch and interbatch precision was within the expected range, $<10 \%$, as stated by the manufacturer.

Dehydroepiandrosterone-sulfate (DHEA-S) and osteocalcin were analyzed by validated methods at GenX Laboratories Inc., Los Angeles, CA, USA.

\section{Statistical analysis}

Pharmacokinetic evaluation was performed using noncompartmental analysis (Phoenix WinNonlin ${ }^{\circledR}$ Version 6.4). AUC was calculated as AUC ${ }_{0-\text { last }+ \text { Clast } / \lambda z}$ in which $C_{\text {last }}$ is the last observed quantifiable concentration. $\lambda \mathrm{z}$ is the rate constant estimated from individual linear regression of the terminal part of the log concentration versus time curve. The $t_{1 / 2}$ was calculated by $\ln (2) / \lambda z$. If $t_{1 / 2}$ was greater than half of the total sampling interval (48 hrs) or the percent extrapolated AUC was $>30 \%$, the terminal elimination phase-dependent parameters ( $t_{1 / 2}$ and AUC) were excluded from descriptive statistics. Observations below LLOQ were set to missing and thus ignored in the analysis.

Due to the exploratory nature of the studies, the sample sizes were not based on formal statistical considerations, but rather on experience from previous similar Phase I studies with other compounds. Descriptive statistics are presented throughout. Dose proportionality was analyzed based on a graphical analysis of dose-adjusted AUC and $\mathrm{C}_{\max }$ and by using the power model approach. The intercept $\alpha$ and the 
slope $\beta$ (in $\left[\mathrm{AUC}\right.$ or $\left.\mathrm{C}_{\max }\right]=\alpha^{*} \operatorname{dose}^{\beta}$ ) together with associated $90 \%$ confidence intervals $(\mathrm{CI})$ was estimated and presented for AUC and $\mathrm{C}_{\max }$. The power model parameters were estimated using least-squares regression. For plasma cortisol, $\mathrm{AUC}_{0-24}$ was calculated, and the AUC ratios of treatment over baseline were compared between treatments using a multiplicative analysis of covariance (ANCOVA). The ratio was also log transformed prior to analysis, with treatment included as the fixed factor and the baseline included as a covariate.

\section{Results}

Twenty-seven Japanese males (mean age 34 years, mean BMI 23) took part in the study, six of them received placebo and 21 received AZD7594. All participants completed the study. The demographic distribution was balanced between treatment groups (Table 1).

\section{Pharmacokinetics}

\section{Single-dose plasma exposure data}

Plasma concentration time data after a single dose of AZD7594 is given in Figure 2A. PK parameters are provided in Table 2. The PK of inhaled AZD7594 was characterized by an initial rapid absorption from the lung, followed by a slow terminal phase, with low sustained concentrations over the $96 \mathrm{hrs}$ sampling period. Consequently, the terminal half-life could only be reliably determined in a few subjects and was estimated to be 40-44 hrs. The data suggested dose-proportional plasma exposure: in a power model dose-adjusted analysis, the $90 \%$ confidence interval $(\mathrm{CI})$ of the slope included 1 both for $\operatorname{AUC}(0.81$ to 1.31$)$ and $\mathrm{C}_{\max }(0.88$ to 1.15$)$. Following single-dose administration, the mean cumulative percent of dose excreted in urine as unchanged drug was less than $0.02 \%$ and mean $\mathrm{CL}_{\mathrm{R}}$ was approximately 0.003 to $0.029 \mathrm{~L} / \mathrm{h}$.

\section{Repeated dose plasma exposure data}

Plasma exposure increased with dose following multiple dosing (Figure 2). PK parameters are provided in Table 3. Overall, after 12 days of once-daily treatment with AZD7594, dose proportionality in PK was shown; the $90 \% \mathrm{CI}$ of the slope included 1 both for $\mathrm{AUC}_{0-24}(0.95$ to 1.14 ) and $\mathrm{C}_{\mathrm{ss}, \max }(0.87$ to 1.09$)$. Following once-daily inhalation of AZD7594, steady state conditions for AZD7594 in plasma were generally reached within eight doses (Figure 3), the accumulation was 3- to 4-fold and data did not indicate any time-dependent PK.

Table I Baseline demographics

\begin{tabular}{|c|c|c|c|c|c|c|}
\hline $\begin{array}{l}\text { Variable } \\
\text { category }\end{array}$ & $\begin{array}{l}\text { Placebo } \\
(\mathrm{N}=6)\end{array}$ & $\begin{array}{l}\text { AZD7594 } 200 \mu \mathrm{g} \\
(\mathrm{N}=7)\end{array}$ & $\begin{array}{l}\text { AZD7594 } 400 \mu \mathrm{g} \\
(\mathrm{N}=7)\end{array}$ & $\begin{array}{l}\text { AZD7594 } 1600 \mu \mathrm{g} \\
(\mathrm{N}=7)\end{array}$ & $\begin{array}{l}\text { Total AZD7594 } \\
(\mathrm{N}=21)\end{array}$ & $\begin{array}{l}\text { All subjects } \\
(\mathrm{N}=27)\end{array}$ \\
\hline \multicolumn{7}{|l|}{ Age (years) } \\
\hline Mean (SD) & $35.7(5.54)$ & $32.7(5.4 I)$ & $34 . I(6.4 I)$ & $33.6(6.43)$ & $33.5(5.82)$ & $34.0(5.73)$ \\
\hline Median & 33.5 & 31.0 & 33.0 & 30.0 & 31.0 & 33.0 \\
\hline Min-Max & $30-44$ & $26-41$ & $28-44$ & $27-43$ & $26-44$ & $26-44$ \\
\hline \multicolumn{7}{|l|}{ Sex, n (\%) } \\
\hline Male & $6(100.0)$ & $7(100.0)$ & $7(100.0)$ & $7(100.0)$ & $21(11.0)$ & $27(100.0)$ \\
\hline \multicolumn{7}{|l|}{ Height $(\mathrm{cm})$} \\
\hline Mean (SD) & $170.2(5.91)$ & I70.4 (7.68) & I $74.7(5.38)$ & $|7| .3(6.21)$ & I72.I (6.44) & I7|.7 (6.27) \\
\hline Median & $|7| .5$ & 170.0 & 177.0 & 171.0 & 172.0 & 172.0 \\
\hline Min-Max & $163-176$ & $161-184$ & $|67-| 8 \mid$ & $162-178$ & $161-184$ & $161-184$ \\
\hline \multicolumn{7}{|l|}{ Weight (kg) } \\
\hline Mean (SD) & $68.02(7.72)$ & $65.83(8.22)$ & $72.53(8.03)$ & $65.69(3.75)$ & 68.01 (7.39) & 68.01 (7.39) \\
\hline Median & 67.45 & 63.30 & 72.60 & 65.00 & 66.60 & 66.90 \\
\hline Min-Max & $58.0-78.6$ & $56.4-81.9$ & $63.8-86.9$ & $59.2-70.3$ & $56.4-86.9$ & $65.4-86.9$ \\
\hline \multicolumn{7}{|l|}{ BMI $\left(\mathrm{kg} / \mathrm{m}^{2}\right)$} \\
\hline Mean (SD) & $23.43(1.77)$ & $22.70(2.92)$ & $23.74(2.03)$ & $22.39(2.14)$ & $22.98(2.343)$ & $23.08(2.20)$ \\
\hline Median & 23.15 & 22.40 & 23.80 & 22.90 & 22.90 & 22.90 \\
\hline Min-Max & $21.8-25.7$ & 19.7-28.3 & $21.2-26.5$ & | $8.7-24.4$ & | $8.7-28.3$ & | $8.7-28.3$ \\
\hline
\end{tabular}

Abbreviations: BMI, body mass index (weight $[\mathrm{kg}] /$ height $\left[\mathrm{m}^{2}\right]$ ); Max, maximum recorded values; Min, minimum recorded values; $\mathrm{n}$, number of subjects in the given category; $\mathrm{N}$, number of subjects randomized to each treatment overall; \%, $\mathrm{n}$ expressed as a percentage of $\mathrm{N}$; SD, standard deviation. 

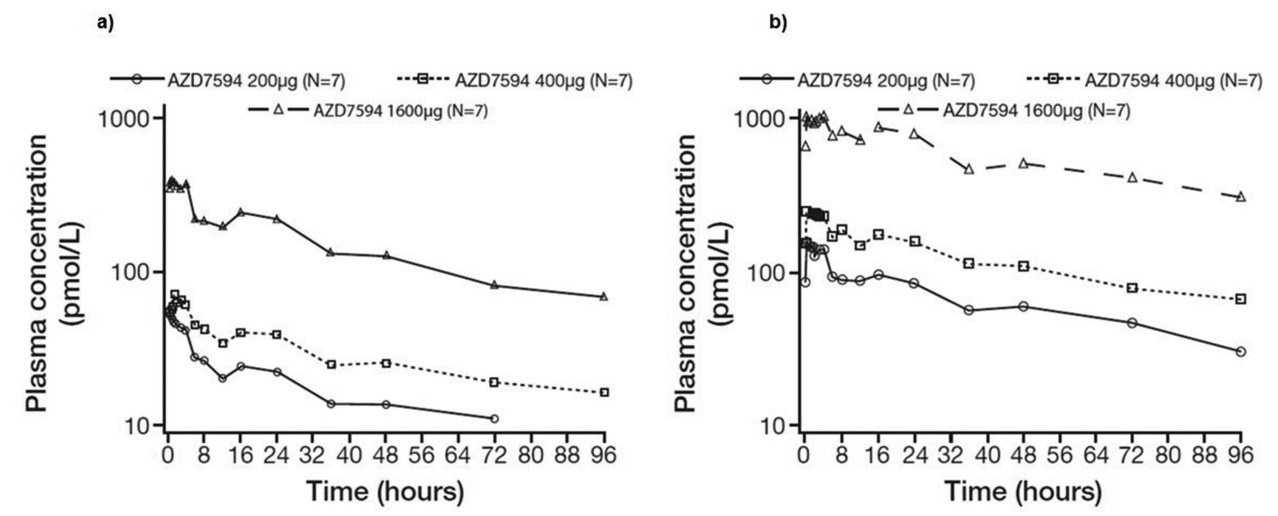

Figure 2 Geometric mean plasma concentrations of AZD7594 in Japanese subjects following a single inhaled dose (a) and following 12 days of once-daily inhalation (b). Note: Figure illustrates semi-logarithmic data and doses are depicted as $\mu \mathrm{g}$ delivered dose.

Table 2 PK parameters of AZD7594 following single inhaled dose, geometric mean (CV\%)

\begin{tabular}{|c|c|c|c|c|}
\hline Parameter (unit) & Summary statistics & $200 \mu g(N=7)$ & $400 \mu g(N=7)$ & $1600 \mu g(N=7)$ \\
\hline$C_{\max }(\mathrm{pmol} / \mathrm{L})$ & $\begin{array}{l}\text { Geometric mean } \\
(\mathrm{CV} \%)\end{array}$ & $\begin{array}{l}56.05 \\
(22.0)\end{array}$ & $\begin{array}{l}76.93 \\
(34.4)\end{array}$ & $\begin{array}{l}430.8 \\
(22.4)\end{array}$ \\
\hline AUC (h*pmol/L) & $\begin{array}{l}\text { Geometric mean } \\
(\mathrm{CV} \%)\end{array}$ & $\begin{array}{l}\mathrm{NC} \\
(\mathrm{NA})\end{array}$ & $\begin{array}{l}\mathrm{NC} \\
(\mathrm{NA})\end{array}$ & $\begin{array}{l}18260^{\mathrm{a}} \\
(22.9)\end{array}$ \\
\hline$A \cup C_{(0 \text {-last })}\left(h^{*}\right.$ pmol/L) & $\begin{array}{l}\text { Geometric mean } \\
(\mathrm{CV} \%)\end{array}$ & $\begin{array}{l}1314 \\
(28.2)\end{array}$ & $\begin{array}{l}2736 \\
(12.2)\end{array}$ & $\begin{array}{l}13,960 \\
(18.2)\end{array}$ \\
\hline $\mathrm{t}_{\max }(\mathrm{h})$ & $\begin{array}{l}\text { Median } \\
\text { (min; max) }\end{array}$ & $\begin{array}{l}0.25 \\
(0.25 ; 0.98)\end{array}$ & $\begin{array}{l}0.52 \\
(0.25 ; 3.00)\end{array}$ & $\begin{array}{l}0.50 \\
(0.25 ; 4.00)\end{array}$ \\
\hline$t_{1 / 2 \lambda z}(h)$ & $\begin{array}{l}\text { Arithmetic mean } \\
\text { (SD) }\end{array}$ & $\begin{array}{l}39.88^{\mathrm{a}} \\
(5.44)\end{array}$ & $\begin{array}{l}\mathrm{NC} \\
(\mathrm{NA})\end{array}$ & $\begin{array}{l}43.57^{\mathrm{b}} \\
(3.815)\end{array}$ \\
\hline $\mathrm{f}_{\mathrm{e}(0 \text {-last })}(\%)$ & $\begin{array}{l}\text { Arithmetic mean } \\
\text { (SD) }\end{array}$ & $\begin{array}{l}0.002 \\
(0.004)\end{array}$ & $\begin{array}{l}0.002 \\
(0.003)\end{array}$ & $\begin{array}{l}0.016 \\
(0.010)\end{array}$ \\
\hline $\mathrm{CL}_{\mathrm{R}}(\mathrm{L} / \mathrm{h})$ & $\begin{array}{l}\text { Arithmetic mean } \\
\text { (SD) }\end{array}$ & $\begin{array}{l}0.003 \\
(0.008)\end{array}$ & $\begin{array}{l}0.005 \\
(0.006)\end{array}$ & $\begin{array}{l}0.029 \\
(0.017)\end{array}$ \\
\hline
\end{tabular}

Notes: ${ }^{a} n=5 ;{ }^{b} n=4$.

Abbreviations: CV\%, geometric coefficient of variation; N, number in the pharmacokinetic analysis set; NA, not applicable; NC, not calculable; SD, standard deviation.

Table 3 PK parameters of AZD7594 following inhaled dosing for 12 days, geometric mean (CV\%)

\begin{tabular}{|c|c|c|c|c|}
\hline Parameter (unit) & Summary statistics & $200 \mu g(N=7)$ & $400 \mu g(N=7)$ & $1600 \mu g(N=7)$ \\
\hline $\mathrm{C}_{\mathrm{ss}, \max }(\mathrm{pmol} / \mathrm{L})$ & $\begin{array}{l}\text { Geometric mean } \\
\text { CV\% }\end{array}$ & $\begin{array}{l}164.3 \\
(14.0)\end{array}$ & $\begin{array}{l}261.2 \\
(37.0)\end{array}$ & $\begin{array}{l}1206 \\
(14.7)\end{array}$ \\
\hline $\mathrm{C}_{\mathrm{av}}(\mathrm{pmol} / \mathrm{L})$ & $\begin{array}{l}\text { Geometric mean } \\
\mathrm{CV} \%\end{array}$ & $\begin{array}{l}101.1 \\
(13.4)\end{array}$ & $\begin{array}{l}183.7 \\
(33.4)\end{array}$ & $\begin{array}{l}867.8 \\
(13.2)\end{array}$ \\
\hline $\mathrm{AUC}_{(0-24)}\left(\mathrm{h}^{*} \mathrm{pmol} / \mathrm{L}\right)$ & $\begin{array}{l}\text { Geometric mean } \\
\mathrm{CV} \%\end{array}$ & $\begin{array}{l}2426 \\
(13.4)\end{array}$ & $\begin{array}{l}4409 \\
(33.4)\end{array}$ & $\begin{array}{l}20,830 \\
(13.2)\end{array}$ \\
\hline$t_{s s, \max }(h)$ & $\begin{array}{l}\text { Median } \\
\text { (min; max) }\end{array}$ & $\begin{array}{l}0.25 \\
(0.25 ; 4.02)\end{array}$ & $\begin{array}{l}1.50 \\
(0.25 ; 8.00)\end{array}$ & $\begin{array}{l}1.50 \\
(0.25 ; 4.00)\end{array}$ \\
\hline $\mathrm{R}_{\mathrm{AC}}$ & $\begin{array}{l}\text { Geometric mean } \\
\text { (SD) }\end{array}$ & $\begin{array}{l}3.562 \\
(15.7)\end{array}$ & $\begin{array}{l}4.067 \\
(43.7)\end{array}$ & $\begin{array}{l}3.437 \\
(7.3)\end{array}$ \\
\hline
\end{tabular}

Abbreviations: CV\%, geometric coefficient of variation; $\mathrm{N}$, number of subjects in the pharmacokinetic analysis set; SD, standard deviation. 


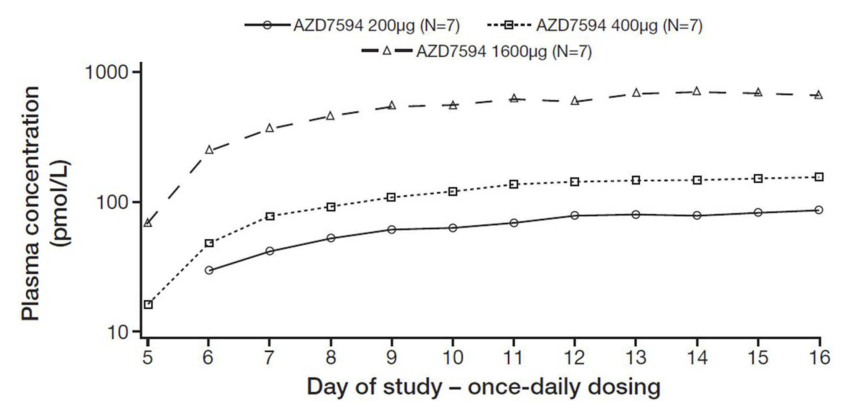

Figure 3 Geometric mean trough plasma concentrations of AZD7594 versus study day.

Note: Figure illustrates semi-logarithmic data and doses are depicted as $\mu g$ delivered dose.

\section{Pharmacodynamics HPA effects}

Plasma concentrations of cortisol after repeated once-daily dosing (at $8 \mathrm{am}$ ) of AZD7594 for 1 day are illustrated in Figure 4. In Table 4, the AZD7594 vs placebo ratios of $\mathrm{AUC}_{0-24}$ hrs plasma cortisol are summarized after single and multiple dosing.

a)

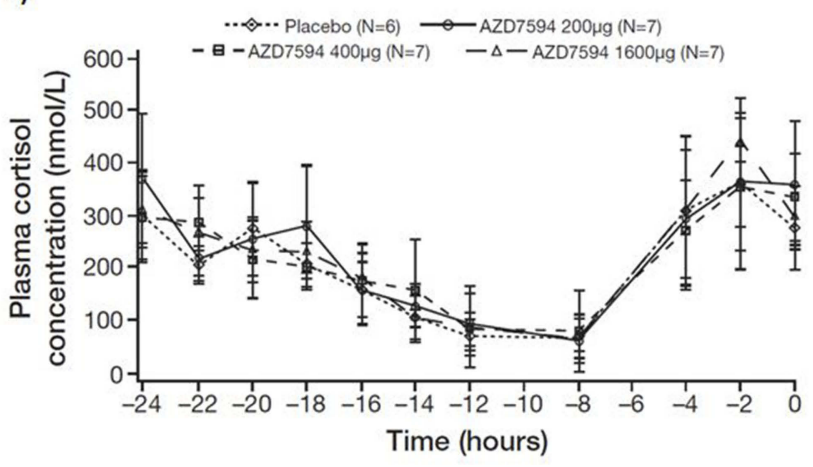

Dose-related effects were observed for plasma cortisol $\mathrm{AUC}_{0-24}$; however, suppression was only statistically significant vs placebo after multiple doses of $1600 \mu \mathrm{g}$ (Table 4). The maximum cortisol suppression was $25 \%$ after $1600 \mu \mathrm{g}$ daily for 12 days. No cortisol suppression was observed following single-dose administration, as compared to placebo.

Plasma cortisol assessments were reproducible and stable throughout treatment periods, as suggested by the placebo $\mathrm{AUC}_{0-24}$ plasma cortisol treatment vs pre-treatment ratio means being close to unity through all treatments. These ratios were 0.90 after single doses and 0.96 after repeated dosing (Table 4).

\section{Other biomarkers}

There was no consistent change in plasma osteocalcin compared to placebo following once-daily dosing of AZD7594 for 12 days, data not shown. No change compared to baseline in mean DHEA-S was observed following 12 days of dosing with placebo. At AZD7594 dose levels $200 \mu \mathrm{g}$ and $400 \mu \mathrm{g}$, the mean values for DHEA-S were numerically slightly lower

b)

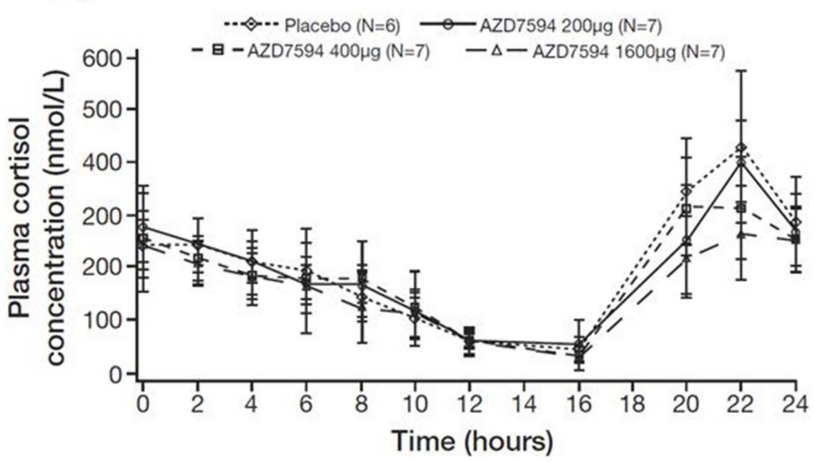

Figure 4 Geometric mean plasma cortisol concentrations at baseline (a) and following 12 days of once-daily morning dosing (b) of AZD7594. Note: Figure illustrates data on a linear scale and doses are depicted as $\mu \mathrm{g}$ delivered dose.

Table 4 Comparison of AZD7594 versus placebo AUC $_{0-24}$ plasma cortisol ratios after single day (Day I) and repeated once-daily dosing for 12 days (Days 5-16)

\begin{tabular}{|c|c|c|c|c|c|c|c|}
\hline & \multirow[t]{2}{*}{ Treatment } & \multirow[t]{2}{*}{$\mathbf{N}$} & \multirow[t]{2}{*}{$\mathbf{n}$} & \multirow[t]{2}{*}{ Geometric LS mean } & \multirow[t]{2}{*}{$95 \% \mathrm{Cl}$} & \multicolumn{2}{|c|}{ Pairwise comparison with placebo } \\
\hline & & & & & & $\begin{array}{l}\text { Ratio } \\
\text { (\%) }\end{array}$ & $95 \% \mathrm{Cl}$ \\
\hline Day I/Day -I & $\begin{array}{l}\text { Placebo } \\
\text { AZD7594 } 200 \mu g \\
\text { AZD7594 } 400 \mu g \\
\text { AZD7594 } 1600 \mu g\end{array}$ & $\begin{array}{l}6 \\
7 \\
7 \\
7\end{array}$ & $\begin{array}{l}7 \\
7 \\
7\end{array}$ & $\begin{array}{l}0.9020 \\
0.9290 \\
0.9554 \\
0.9004\end{array}$ & $\begin{array}{l}0.7960 ; 1.022 \\
0.8282 ; 1.042 \\
0.8518 ; 1.072 \\
0.8024 ; 1.010\end{array}$ & $\begin{array}{l}102.99 \\
105.92 \\
99.82\end{array}$ & $\begin{array}{l}86.88 ; 122.09 \\
89.40 ; 125.49 \\
84.12 ; 118.46\end{array}$ \\
\hline Day I6/Day -I & $\begin{array}{l}\text { Placebo } \\
\text { AZD7594 } 200 \mu g \\
\text { AZD7594 } 400 \mu g \\
\text { AZD7594 } 1600 \mu g\end{array}$ & $\begin{array}{l}6 \\
7 \\
7 \\
7\end{array}$ & $\begin{array}{l}7 \\
7 \\
7\end{array}$ & $\begin{array}{l}0.9627 \\
0.8839 \\
0.8610 \\
0.7256\end{array}$ & $\begin{array}{l}0.8484 ; 1.092 \\
0.787 I ; 0.9927 \\
0.7667 ; 0.9668 \\
0.6458 ; 0.8 I 53\end{array}$ & $\begin{array}{l}91.82 \\
89.44 \\
75.38\end{array}$ & $\begin{array}{l}77.32 ; 109.04 \\
75.35 ; 106.16 \\
63.40 ; 89.61\end{array}$ \\
\hline
\end{tabular}

Abbreviations: $\mathrm{Cl}$, confidence interval; LS, least squares; $\mathrm{N}$, number in the pharmacokinetic analysis set; $\mathrm{n}$, all subjects included in the statistical comparison analysis. 
$(9 \%[-0.612 \mu \mathrm{mol} / \mathrm{L}]$ and $15 \%[-1.130 \mu \mathrm{mol} / \mathrm{L}]$, respectively $)$ compared to baseline. In the $1600 \mu \mathrm{g}$ group, the mean was numerically slightly higher $(5 \%[0.112 \mu \mathrm{mol} / \mathrm{L}])$ compared to the baseline measurement.

\section{Safety and tolerability following inhalation of AZD7594}

Incidences of adverse events are presented in Table 5. There were no clinically relevant patterns in laboratory safety test (clinical chemistry, hematology and urinalysis) results, ECG, vital signs or spirometry measurements during the study. A total of six AEs were reported by six subjects (five AEs reported by $5 / 21$ subjects receiving AZD7594 and one AE reported by $1 / 6$ subjects receiving placebo). There was no identifiable dose-related trend in AEs. For subjects receiving AZD7594, a total of three AEs was reported for the $200 \mu \mathrm{g}$ dose group (dry throat, nasal congestion and oropharyngeal pain). One subject in the $400 \mu \mathrm{g}$ dose group reported folliculitis and there was one report of presyncope in the $1600 \mu \mathrm{g}$ dose group.

Gout of moderate intensity was reported by one subject receiving placebo. All other AEs were of mild intensity. All AEs except dry throat (in AZD7594 $200 \mu \mathrm{g}$ dose group) were considered by the investigator to be not related to the study drug.

\section{Discussion}

The study in healthy Japanese male subjects summarized in this report suggests that inhaled AZD7594 is generally safe and well tolerated in the investigated dose range - up to $1600 \mu \mathrm{g}$ single doses and once-daily delivered doses for 12 days. Both the single and multiple ascending doses suggested dose-proportional plasma exposure of AZD7594. Steady state kinetics were reached in eight days and the accumulation ratio was moderate (3-4). Inhaled AZD7594 did pharmacologically affect the HPA axis (0-24 hrs cortisol data), but only following repeat administration of the highest dose.

As has been previously shown for AZD7594 following inhalation, the compound shows absorption-rate-limited kinetics; ie, the elimination is dependent on the absorption rate from the lung. ${ }^{1}$ The slow absorption, governed by a slow dissolution rate due to low solubility, results in a long pulmonary residence time and supports once-daily administration. The prolonged absorption phase resulted in low and sustained concentrations observed through the last sample collection time-point of $96 \mathrm{hrs}$. It was not possible to determine the terminal half-life accurately for many subjects due to an insufficient sampling interval; the reported means are thus underestimations of the true half-life. Individual subject $t_{1 / 2}$ values ranged from 34.8 to $93 \mathrm{hrs}$ and were similar to a recent study, where the same DPI device and formulation was used and individual subject $t_{1 / 2}$ values ranged from 27.1 to $83.4 \mathrm{hrs} .{ }^{1}$ The results in the present study, however, were notably longer than those in another previous study, ${ }^{3}$ in which healthy volunteers reported mean $t_{1 / 2}$ values of approximately 22 to $31 \mathrm{hrs}$ after administration of AZD7594 suspension via nebulizer,

Table 5 Adverse events

\begin{tabular}{|c|c|c|c|c|c|c|}
\hline $\begin{array}{l}\text { System Organ Class/ Preferred } \\
\text { Term }\end{array}$ & $\begin{array}{l}\text { Placebo } \\
(\mathbf{N}=6) \\
n(\%)\end{array}$ & $\begin{array}{l}\text { AZD7594 } \\
200 \mu \mathrm{g} \\
(\mathrm{N}=7) \\
\mathrm{n}(\%)\end{array}$ & $\begin{array}{l}\text { AZD7594 } \\
400 \mu \mathrm{g} \\
(\mathrm{N}=7) \\
\mathrm{n}(\%)\end{array}$ & $\begin{array}{l}\text { AZD7594 } \\
\text { I } 600 \mu \mathrm{g} \\
(\mathrm{N}=7) \\
\mathrm{n}(\%)\end{array}$ & $\begin{array}{l}\text { Total AZD7594 } \\
(\mathrm{N}=2 \mathrm{I}) \\
\text { n (\%) }\end{array}$ & $\begin{array}{l}\text { All subjects } \\
(\mathrm{N}=27), \mathrm{n}(\%)\end{array}$ \\
\hline Subjects with any $A E$ & I (I6.7) & $3(42.9)$ & I (14.3) & I (14.3) & $5(23.8)$ & $6(22.2)$ \\
\hline $\begin{array}{l}\text { Respiratory, thoracic and } \\
\text { mediastinal disorders }\end{array}$ & 0 & $3(42.9)$ & 0 & 0 & $3(42.9)$ & $3(11.1)$ \\
\hline Dry throat & 0 & I (I4.3) & 0 & 0 & I (4.8) & I (3.7) \\
\hline Nasal congestion & 0 & I (14.3) & 0 & 0 & I (4.8) & I (3.7) \\
\hline Oropharyngeal pain & 0 & I (I4.3) & 0 & 0 & I (4.8) & I (3.7) \\
\hline Infections and infestations & 0 & 0 & I (I4.3) & 0 & I (4.8) & I (3.7) \\
\hline Folliculitis & 0 & 0 & I (14.3) & 0 & I (4.8) & I (3.7) \\
\hline $\begin{array}{l}\text { Metabolism and nutritional } \\
\text { disorders }\end{array}$ & I (I6.7) & 0 & 0 & 0 & 0 & I (3.7) \\
\hline Gout & I (16.7) & 0 & 0 & 0 & 0 & I (3.7) \\
\hline Nervous system disorders & 0 & 0 & 0 & I (I4.3) & I (4.8) & I (3.7) \\
\hline Presyncope & 0 & 0 & 0 & I (14.3) & I (4.8) & I (3.7) \\
\hline
\end{tabular}

Abbreviations: $A E$, adverse event; $N$, number of subjects randomized to each treatment or overall; $n$ (\%), number of subjects in each category expressed as a percentage of $N$. 
confirming that the elimination process of AZD7594 is drug delivery and absorption rate-limited.

Following single-dose administration, the mean cumulative percent of dose excreted in urine as unchanged drug was less than $0.02 \%$ and mean CLR was approximately 0.003 to $0.029 \mathrm{~L} / \mathrm{h}$, suggesting that urinary excretion is a negligible elimination pathway for AZD7594.

Previously, the basic pharmacokinetic properties of AZD7594 have been described after single doses in healthy subjects. ${ }^{1}$ Disposition was multi-phasic, hepatic clearance high and oral availability less than $1 \%$. Hence, the basic PK properties of AZD7594 are similar to those of other currently available GR agonists, notably the inhaled corticosteroids.

The plasma concentration time data in this study do not suggest any significant ethnic difference in AZD7594 dose-normalized plasma exposure (AUC) or any effect on cortisol suppression, taking into consideration the different administration techniques (nebulization in the recent Caucasian-dominant SAD-MAD study ${ }^{3}$ vs DPI in this study). No difference in exposure between the two populations was expected. The metabolism of AZD7594 has been investigated using heterologous expressed human cytochrome $\mathrm{P} 450$ isoforms. The results indicate that AZD7594 is mainly metabolized by CYP3A4 with a minor contribution of CYP2C9. The activity of CYP3A4 in vivo is essentially similar in subjects of Japanese, Korean, Chinese and Caucasian ancestry. ${ }^{6}$ In the present study, the systemic pharmacodynamic effects were studied in healthy Japanese subjects. As expected, effects on HPA function increase with dose of inhaled AZD7594: maximal suppression of 24-hrs plasma cortisol was $25 \%$, attained after the highest dose, $1600 \mu \mathrm{g}$ daily dose for 12 days. There was no significant cortisol suppression seen at lower doses in the dose range expected to be advanced further in later phase clinical studies. Effect on osteocalcin, a sensitive biomarker of bone formation, was marginal. No effect was seen on DHEA-S, a steroidal adrenal hormone affected by exogenous corticosteroid exposure but with the advantage of lacking diurnal variation. ${ }^{7}$ It should be kept in mind that the data sets reported herein are small, and that effects may have been revealed in other and/or larger cohorts of subjects. In conclusion, the early clinical evaluation of inhaled AZD7594 suggests that this novel SGRM is well tolerated in Japanese subjects as single and multiple (12 days once-daily) administrations in the dose range investigated (200-1600 $\mu \mathrm{g}$ delivered dose). AZD7594 shows dose-proportional plasma exposure, moderate accumulation and has little impact on systemic markers of glucocorticoid activity. In retrospective comparison to data from studies in Caucasian healthy volunteers, there is nothing to suggest that Japanese subjects have a relevant difference in their systemic plasma exposure or in $24 \mathrm{hr}$ plasma cortisol after inhaled administration of AZD7594.

\section{Data sharing statement}

Data underlying the findings described in this manuscript may be obtained in accordance with AstraZeneca's data sharing policy, described at: https://astrazenecagrouptrials. pharmacm.com/ST/Submission/Disclosure.

\section{Abbreviations}

AUC, area under the curve; DHEA-S, dehydroepiandrosterone sulfate; HPA, hypothalamic-pituitary-adrenal axis; ICS, inhaled corticosteroids; MAD, multiple ascending dose; PK, pharmacokinetics; PD, pharmacodynamics; $\mathrm{SAD}$, single ascending dose; SGRM, selective glucocorticoid receptor modulator.

\section{Acknowledgments}

We thank the volunteers who participated in this study, and the former AstraZeneca colleagues Hong-Lin Su for statistical planning and evaluation and Mats Bjersing for study coordination. This study was conducted in collaboration with PAREXEL. Editorial assistance was provided by David Candlish and Sophieanne Wastling of inScience Communications, Springer Healthcare Ltd, UK, which was funded by AstraZeneca in accordance with Good Publication Practice (GPP3) guidelines (http://www.ismpp.org/gpp3). This study was funded by AstraZeneca.

\section{Disclosure}

SP, UT, YC, HF, CA, AA, and UWH are all current or former employees of AstraZeneca. EY is an employee of PAREXEL. AstraZeneca provided funding to PAREXEL for the conduct of this study. SP owns shares in AstraZeneca. UT reports personal fees from AstraZeneca, during the conduct of the study and owns shares in AstraZeneca. HF owns shares in AstraZeneca. The authors report no other conflicts of interest in this work. 


\section{References}

1. Chen Y, Prothon S, Su H-L, et al. Pharmacokinetics (PK) of a single dose AZD7594 administered intravenously (IV), orally, and inhaled via two dry powder inhalers (DPI) and a pressurized metered-dose inhaler (pMDI). Paper presented at: ERS (European Respiratory Society); 2017; Milan, Italy.

2. Hemmerling $M$, Nilsson S, Edman K, et al. Selective nonsteroidal glucocorticoid receptor modulators for the inhaled treatment of pulmonary diseases. J Med Chem. 2017;60:8591-8605. doi:10.1021/acs. jmedchem.7b01215.

3. Chen Y, Prothon S, Aurivillius M, Eriksson UG, Aggarwal A Safety, tolerability, pharmacokinetics (PK), and pharmacodynamics (PD) of AZD7594 after single and multiple ascending inhaled doses in healthy male volunteers. Paper presented at: ASCPT (American Society for Clinical Pharmacology \& Therapeutics); 2016; San Diego, USA.
4. Brown M, Fuhr R, Su H-L, et al. A randomized trial of AZD7594 a novel non-steroidal anti-inflammatory drug in asthma patients. Paper presented at: ERS (European Respiratory Society); 2017; Milan, Italy.

5. Brown MN, Fuhr R, Beier J, et al. Efficacy and safety of AZD7594, an inhaled non-steroidal selective glucocorticoid receptor modulator, in patients with asthma: a phase $2 \mathrm{a}$ randomized, double blind, placebocontrolled crossover trial. Respir Res. 2019;20(1):37. doi:10.1186/ s12931-019-1000-7.

6. Myrand SP, Sekiguchi K, Man MZ, et al. Pharmacokinetics/genotype associations for major cytochrome P450 enzymes in native and firstand third-generation Japanese populations: comparison with Korean, Chinese, and Caucasian populations. Clin Pharmacol Ther. 2008;84 (3):347-361. doi:10.1038/sj.clpt.6100482

7. Sahiner UM, Cetinkaya S, Ozmen S, Arslan Z. Evaluation of adrenocortical function in 3-7 aged asthmatic children treated with moderate doses of fluticasone propionate: reliability of dehydroepiandrosterone sulphate as a screening test. Allergol Immunopathol. 2010;39:154-158. doi:10.1016/j.aller.2010.06.005

\section{Publish your work in this journal}

Drug Design, Development and Therapy is an international, peerreviewed open-access journal that spans the spectrum of drug design and development through to clinical applications. Clinical outcomes, patient safety, and programs for the development and effective, safe, and sustained use of medicines are a feature of the journal, which has also been accepted for indexing on PubMed Central. The manuscript management system is completely online and includes a very quick and fair peer-review system, which is all easy to use. Visit http://www. dovepress.com/testimonials.php to read real quotes from published authors. 